\title{
Analysis of cell cycle shortening and developmental interruption in Dictyostelium discoideum allC RNAi mutants
}

\author{
D.M. Xue, L.S. Hou, S.R. Zhang and N.X. Chen \\ School of Life Science, East China Normal University, Shanghai, China \\ Corresponding authors: L.S. Hou / D.M. Xue \\ E-mail: 1shou@bio.ecnu.edu.cn / xuedeming2003@aliyun.com
}

Genet. Mol. Res. 13 (2): 3956-3966 (2014)

Received February 4, 2013

Accepted July 17, 2013

Published May 23, 2014

DOI http://dx.doi.org/10.4238/2014.May.23.6

\begin{abstract}
Dictyostelium discoideum allC RNAi mutant cells are motile and aggregate together, but do not undergo further morphological development. The relatively quick growth rate of allC RNAi mutants compared to wild-type $D$. discoideum results in a shortened mutant cell cycle. However, at present, little is known about the mechanism underlying this phenomenon. Here, we used semi-quantitative reverse transcription-polymerase chain reaction (RT-PCR), realtime quantitative RT-PCR, two-dimensional gel electrophoresis, and mass spectrometry/mass spectrometry to elucidate the phenomenon. We found significant downregulation of myosin II heavy chain, $D$. discoideum calcium-dependent cell adhesion molecule-1 (DdCAD-1) mRNA, DdCAD-1 protein, D. discoideum mRNA for 14-3-3 and 14-33 protein, and type A von Willebrand factor domain-containing protein mRNA in allC RNAi mutants. The results suggest that downregulation of the myosin II heavy chain could be one of key factors causing the developmental interruption and that downregulation of the 14-3-3 protein and the type A von Willebrand factor domain-containing protein
\end{abstract}


mRNA plays an important role in shortening the cell cycle of allC RNAi mutants.

Key words: Dictyostelium discoideum allC RNAi mutant; Myosin II heavy chain; 14-3-3 protein;

Type A von Willebrand factor domain-containing protein

\section{INTRODUCTION}

The social amoeba Dictyostelium discoideum has been used as a model organism in many important biological fields of study, ranging from social biology to medical sciences (Williams, 2010). There are many experimental advantages associated with this organism. D. discoideum has a simple and well-defined life cycle and is amenable to various molecular and cellular manipulations. The amoeboid cells feed on bacteria and multicellular development is triggered upon depletion of food. The developmental cascade can be divided into an aggregation phase and a post-aggregation phase, each lasting for $\sim 12 \mathrm{~h}$. During the first 6-8 h, cells exit in the solitary state to adopt a social behavior, which allows them to interact and undergo chemotaxis in response to extracellular cyclic adenosine monophosphate (cAMP) (Parent and Devreotes, 1996). Cell-cell interactions are established via cell adhesion molecules (CAMs) in cell streams, which eventually give rise to loose mound structures. Then, cells secrete extracellular matrix material, which forms a slime sheath to encase the developing structure (Loomis Jr, 1972). The appearance of tight mounds demarcates the beginning of the post-aggregation phase. Cellular movement in mounds promotes morphogenesis of the tipped mound, which extends into a long finger-like structure and transforms into a migratory slug (Weijer, 2009). Culmination starts with the slug rearing up on its posterior end and prestalk cells migrate downward in a tubular structure to form a nascent stalk, giving rise to a fruiting body composed of a sorus of spores atop a filamentous stalk.

During vertebrate evolution, the purine catabolism pathway was differently truncated, with the possible advantage of preserving water. Consequently, the activity of the enzymes involved in this pathway, as well as its end products, vary from species to species. One of the enzymes in this pathway, allantoicase, most likely appeared very early during evolution, but its activity appears to have been lost over the course of vertebrate evolution (Keilin, 1959), as it is present in most fish and amphibians, but not in amniotes (Urich, 1994). Because little is currently known about the mechanism of this phenomenon, we constructed a D. discoideum allC RNAi mutant to elucidate the mechanism for the loss of allantoicase during animal evolution.

$D$. discoideum allC RNAi mutant cells have a shorter cell cycle, a reduction in cellular size, and an interruption of development relative to wild type D. discoideum (Xue and Hou, 2012). $\mathrm{NH}_{3}$ is one of the downstream metabolic products catalyzed by allantoicase. Although RNAi-silenced expression of allantoicase was shown to reduce levels of intracellular $\mathrm{NH}_{3} / \mathrm{NH}_{4}^{+}$to evoke pleiotropic cellular responses, little is known about the details of this mechanism at present.

In the present study, we used semi-quantitative reverse transcription-polymerase chain reaction (RT-PCR), real-time quantitative RT-PCR (qRT-PCR), two-dimensional gel electrophoresis, and mass spectrometry/mass spectrometry (MS/MS) to elucidate this phenomenon. 


\section{MATERIAL AND METHODS}

\section{Cell strain and culture}

The D. discoideum KAx3 strain and allC RNAi mutants were cultured at $22^{\circ} \mathrm{C}$ in axenic medium HL5 (Sussman, 1987).

\section{Real-time qRT-PCR analysis}

$\mathrm{KAx} 3$ and allC RNAi mutant cells were grown at $22^{\circ} \mathrm{C}$ in axenic medium HL5. Exponentially growing cells were harvested. Total RNA was extracted according to TaKaRa RNAiso ${ }^{\text {TM }}$ Plus specifications. Real-time qRT-PCR was conducted using the CFX96 ${ }^{\mathrm{TM}}$ Real-Time System (Bio-Rad, USA). The following gene-specific primers, which were designed according to GenBank sequences, were used: D. discoideum mRNA for the 14-3-3 protein (GI: 1197462), 5'-aatgttattggtgctcgtcgt$3^{\prime}$ and 5'-aatgtcggtaagttcetttcg-3'; type A von Willebrand factor domain-containing protein mRNA (GI: 66807688), 5'-tctgatggagaaggggattg-3' and 5'-agaggatgacgatgaagacga-3'; DdCAD-1 mRNA (GI: 1224120), 5'-aactgcactggtgaatcatttg-3' and 5'-cattgtttgtactgccttgagc-3'. The specificity of the amplified products was evaluated through the analysis of the dissociation curves generated by the equipment. The relative expression levels of three genes between wild type and allC RNAi mutants were calculated by the formula: Ratio ${ }_{(\text {test } / \text { calibrator) }}=E^{C T \text { (calibrator)-CT(test) }}$.

Real-time qPCR amplification reactions were carried out in a final volume of $25 \mu \mathrm{L}$, which contained $12.5 \mu \mathrm{L} 2 \mathrm{X}$ SYBR Premix Ex Taq ${ }^{\mathrm{TM}}$ (TaKaRa, Japan), $0.5 \mu \mathrm{L}$ diluted template containing $50 \mathrm{ng}$ cDNA, $11.0 \mu \mathrm{L}$ PCR-grade water, and $0.5 \mu \mathrm{L}$ each primer. PCR conditions were as follows: pre-denaturation at $95^{\circ} \mathrm{C}$ for $30 \mathrm{~s}$ and 39 cycles each of denaturation at $95^{\circ} \mathrm{C}$ for $5 \mathrm{~s}$, annealing at $55^{\circ} \mathrm{C}$ for $30 \mathrm{~s}$, and elongation at $72^{\circ} \mathrm{C}$ for $30 \mathrm{~s}$. The resultant data were analyzed using the CFX Manager ${ }^{\mathrm{TM}}$ software (version 1.0).

\section{Semi-quantitative RT-PCR}

An aliquot of the PCR products obtained from the procedure described above were subjected to electrophoresis on a 1.5\% agarose gel and stained with GoldView. Images of the RT-PCR GoldView-stained agarose gels were acquired with the Gel Image System Tanon 2500 , and quantification of the bands was performed using the Image J software. Statistical analyses were carried out with Office Excel 2003.

\section{Protein sample preparation}

Exponentially growing wild-type $\left(3.75 \times 10^{7}\right.$ cells $)$ and allC RNAi mutant cells $(3.75 \mathrm{x}$ $10^{8}$ cells) were harvested; washed three times in MilliQ water; solubilized in $500 \mu \mathrm{L}$ extraction buffer consisting of $7 \mathrm{M}$ urea, $2 \mathrm{M}$ thiourea, 4\% 3-[(3-cholamidopropyl) dimethylammonio]1-propanesulfonate (CHAPS), $40 \mathrm{mM}$ dithiothreitol (DTT), and 2\% Bio-Lyte 3-10 per $10 \mathrm{~mL}$ of extraction buffer; vibrated at room temperature for $1 \mathrm{~h}$; and centrifuged at 13,000 $\mathrm{x} g$ for 1 $\mathrm{h}$ at $4^{\circ} \mathrm{C}$. The supernatants containing the total proteins were transferred into Eppendorf tubes and stored at $-80^{\circ} \mathrm{C}$ for use. Protein concentration determination was carried out using a commercial RC DC ${ }^{\mathrm{TM}}$ Protein Assay kit (BIO-RAD, USA) according to manufacturer protocols. 


\section{Two-dimensional gel electrophoresis}

The $7 \mathrm{~cm}$ immobilized $\mathrm{pH}$ gradient (IPG) strips (pH 4-7, L, BioRad) were rehydrated for $16 \mathrm{~h}$ in $150 \mu \mathrm{L}$ supernatant containing $350 \mu \mathrm{g}$ protein at room temperature. Isoelectric focusing (IEF) was then carried out following manufacturer instructions in the Protein IEF cell apparatus (BioRad). The sample focusing conditions were as follows: $250 \mathrm{~V}$ linear for 30 min, $500 \mathrm{~V}$ rapid for $30 \mathrm{~min}, 40,000 \mathrm{~V}$ linear for $3 \mathrm{~h}, 4000 \mathrm{~V}$ rapid for $20,000 \mathrm{Vh}$, and $500 \mathrm{~V}$ rapid for $24 \mathrm{~h}$. The limit of current was $30 \mu \mathrm{A}$. When the IEF was finished, the IPG strips were equilibrated two times for 20 min with $37.5 \mathrm{mM}$ Tris-HCl, pH 8.8, $6 \mathrm{M}$ urea, $20 \%$ glycerol, and $2 \%$ sodium dodecyl sulfate (SDS), $2 \%$ DTT, or $2.5 \%$ iodoacetamide (each strip in $2.5 \mathrm{~mL}$ solution). DTT was used 1st for $10 \mathrm{~min}$, and iodoacetamide was used $2 \mathrm{nd}$ for $10 \mathrm{~min}$. The strips were then transferred onto 12\% SDS-polyacrylamide gel electrophoresis (PAGE) gels for two-dimensional separation. To obtain the pooled samples of wild type and allC RNAi mutant cells, two-dimensional gel electrophoresis (2-DE) runs were repeated three times.

\section{Protein staining, image acquisition, and analysis}

After electrophoresis, the gels were stained with Coomassie brilliant blue R-250 according to the Bio-Rad methods for 2-D electrophoresis in proteomics. The stain was prepared according to the following protocol: $227 \mathrm{~mL}$ MilliQ water solution containing $1.25 \mathrm{~g}$ Coomassie brilliant blue R-250, $227 \mathrm{~mL}$ methanol, and $46 \mathrm{~mL}$ glacial acetic acid. Gels were washed once in MilliQ water, and then placed in the stain for $1 \mathrm{~h}$ with gentle agitation in an orbital shaker. The gels were then destained in a destainer until the proteins appeared blue on a clear background.

JPEG-format images used for image analysis were achieved with the Gel Image System Tanon 2500. Protein spots in gels were identified according to the two-dimensional coordinates, in which $\mathrm{pH}$ was the abscissa and the protein molecular weight marker was the ordinate.

\section{Protein identification by matrix-assisted laser desorption/ionization-time of flight/ time-of flight}

The protein spots were excised from the gels, placed in Eppendorf tubes, and sequentially decolorized with decolorizing solution $\left[25 \mathrm{mM} \mathrm{NH}_{4} \mathrm{HCO}_{3}, 50 \%\right.$ acetonitrile (ACN)] in ultrasonic wave for 5 min per time period, until the gel particle was colorless. Next, the gel pieces were shrunk in $100 \% \mathrm{ACN}$, air-dried at room temperature, and then rehydrated with 3 $\mu \mathrm{L}$ trypsin solution ( $25 \mathrm{mM} \mathrm{NH}_{4} \mathrm{HCO}_{3}$ containing $1 \%$ sequence-grade trypsin) at $4^{\circ} \mathrm{C}$ for 30 min. Finally, $10 \mu \mathrm{L} 25 \mathrm{mM} \mathrm{NH}_{4} \mathrm{HCO}_{3}$ was added and incubated overnight at $37^{\circ} \mathrm{C}$. An aliquot of $1 \mu \mathrm{L}$ matrix [0.4 mg/mL HCCA in AT (ACN: $0.1 \%$, TFA $=70: 30)]$ was spotted onto MTP AnchorChip ${ }^{\text {TM }}$ 800/384 target plates (Bruker Dalton, Germany). After the matrix was dried, $1 \mu \mathrm{L}$ peptide fragments was spotted onto corresponding target plates. The peptide mass spectra were obtained with a matrix-assisted laser desorption/ionization-time of flight/time-of flight (MALDI-TOF/TOF) mass spectrometer (AutoFlexIII, Bruker Dalton, Germany). Peptide mass fingerprinting (PMF) was obtained in the mass range of 700 to $4000 \mathrm{Da}$, with a focus mass of $2000 \mathrm{Da}$. The peptide calibration standard II (Bruker Dalton) was used as a correction internal standard, and the peptide mass tolerances of PMF and MS/MS were $100 \mathrm{ppm}$ and 70 ppm, respectively. The minimum S/N filter was 20. A MASCOT search engine (version 2.3) was used to search all of the tandem mass spectra. Biotools were used to create and search files 
with the MASCOT search for peptide and protein identification. Cysteine carbamidomethylation $(\mathrm{C})$ and methionine oxidation $(\mathrm{M})$ were selected as fixed and variable modifications, respectively. The trypsin digestion was chosen, and one missing cleavage was allowed at most.

\section{RESULTS}

Downregulation of mRNA for 14-3-3 protein (GI: 1197462), type A von Willebrand factor domain-containing protein mRNA (GI: 66807688), and DdCAD-1 mRNA (GI: 1224120) in allC RNAi mutants

To analyze the cause of the shortened cell cycle and developmental interruption in allC RNAi mutants, we measured mRNA of the 14-3-3 protein, the type A von Willebrand factor domain-containing protein mRNA, and the DdCAD-1 mRNA with real-time qRT-PCR and semi-quantitative RT-PCR.

For mRNA of the 14-3-3 protein, the mean cycle threshold $\left(\mathrm{C}_{\mathrm{T}}\right)$ values for KAx3 wild type and allC RNAi mutant cells were 23.06 and 38.06 , respectively. The mean of relative quantity of 14-3-3 protein mRNA in the KAx3 wild type was 33630.85, and the standard deviation was 6417.12 . The mean relative quantity of $14-3-3$ protein mRNA in allC RNAi mutants was 1.05 , and the standard deviation was 0.02 . There was a very significant difference observed in mRNA of the 14-3-3 protein between the KAx3 wild type and allC RNAi mutants $(\mathrm{P}<0.001)$. The mRNA expression level of the 14-3-3 protein in allC RNAi mutants was obviously reduced when compared to that of the KAx3 wild type.

To further verify if the 14-3-3 protein mRNA decreased in allC RNAi mutants, we used semi-quantitative RT-PCR. There was significant downregulation in expression in allC RNAi mutants compared with the wild type $(\mathrm{P}<0.05)$ (Figure 1). This result was in substantial agreement with that obtained by real-time qRT-PCR.
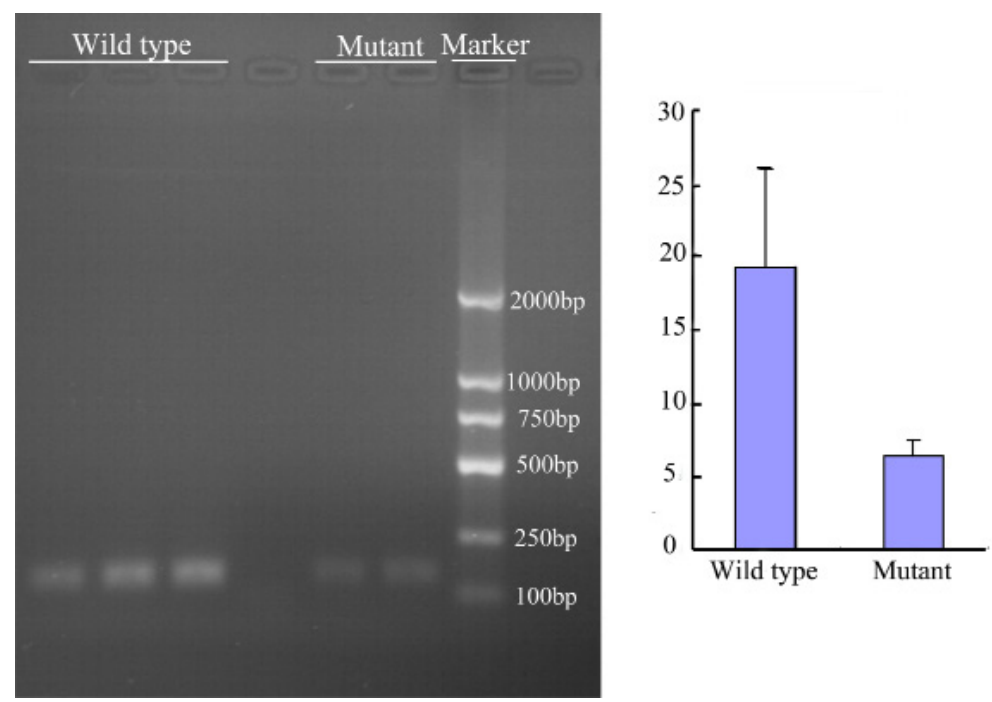

Figure 1. Expression of mRNA for 14-3-3 protein in wild type and allC RNAi mutant with the semiquantitative RT-PCR. Bar graph represents means $\pm \mathrm{SD}$. 
For the type A von Willebrand factor domain-containing protein mRNA, the mean $\mathrm{C}_{\mathrm{T}}$ values for the KAx3 wild type and allC RNAi mutant cells were 29.29 and $\infty$, respectively. This indicated that the allC RNAi mutant did not express the type A von Willebrand factor domain-containing protein mRNA.

To further verify if the type A von Willebrand factor domain-containing protein mRNA was expressed in the allC RNAi mutant, we used semi-quantitative RT-PCR. There was no band produced in the allC RNAi mutant (Figure 2). This result was in substantial agreement with that obtained by real-time qRT-PCR.

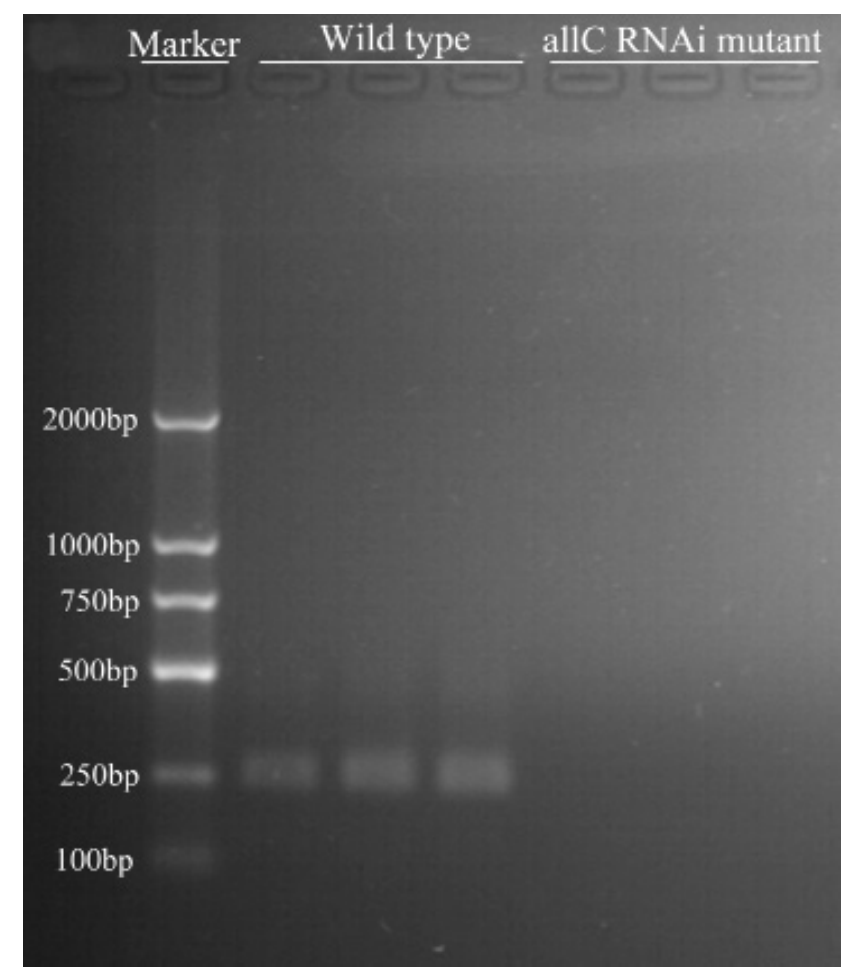

Figure 2. Expression of type A von Willebrand factor domain-containing protein mRNA in wild type and allC RNAi mutant with the semiquantitative RT-PCR.

For DdCAD-1 mRNA, the mean $\mathrm{C}_{\mathrm{T}}$ values for the KAx3 wild type and allC RNAi mutant cells were 22.65 and 36.85 , respectively. The mean relative quantity of DdCAD-1 mRNA in the KAx3 wild type was 21555.96, and the standard deviation was 4121.16. The mean relative quantity of DdCAD-1 mRNA in the allC RNAi mutant was 1.14, and the standard deviation was 0.14 . There was a very significant difference in DdCAD-1 mRNA expression between the KAx3 wild type and the allC RNAi mutant $(\mathrm{P}<0.001)$. The expression level of DdCAD-1 mRNA was obviously reduced in the allC RNAi mutant when compared to the KAx3 wild type.

To further verify if DdCAD-1 mRNA decreased in the allC RNAi mutant, we used semi-quantitative RT-PCR. There was significant downregulation in expression in the allC 
RNAi mutant compared with the wild type $(\mathrm{P}<0.01)$ (Figure 3). This result was in substantial agreement with that obtained by real-time qRT-PCR.
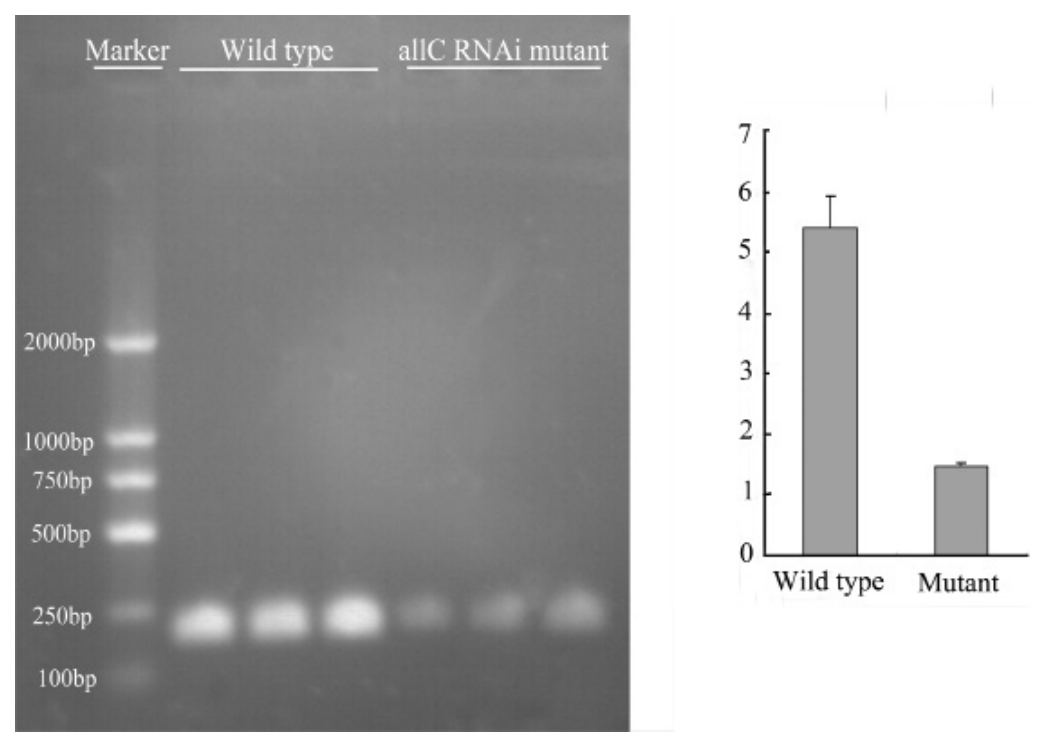

Figure 3. Expression of DdCAD-1 mRNA in wild type and allC RNAi mutant with the semiquantitative RT-PCR. Bar graph represents means $\pm \mathrm{SD}$.

\section{Downregulation of 14-3-3 protein (GI: 1197463), myosin II heavy chain (GI: 167835), and DdCAD-1 (GI: 1705539) in allC RNAi mutants}

In the 2-DE experiments, we carried out three independent repetitions with three paired cultures, and identified three differentially expressed protein spots that were in positions No. 1, No. 2, and No. 3, respectively. There were clear spots observed at positions No. 1, No. 2, and No. 3 on the gel of the KAx3 wild type, but no spots were observed on the gel of the allC RNAi mutant (Figures 4 and 5). Three spots were identified by MALDI-TOF-MS/ MS (Table 1). The results indicated that the 14-3-3 protein, the myosin II heavy chain, and DdCAD-1 were all substantially downregulated in the allC RNAi mutant.

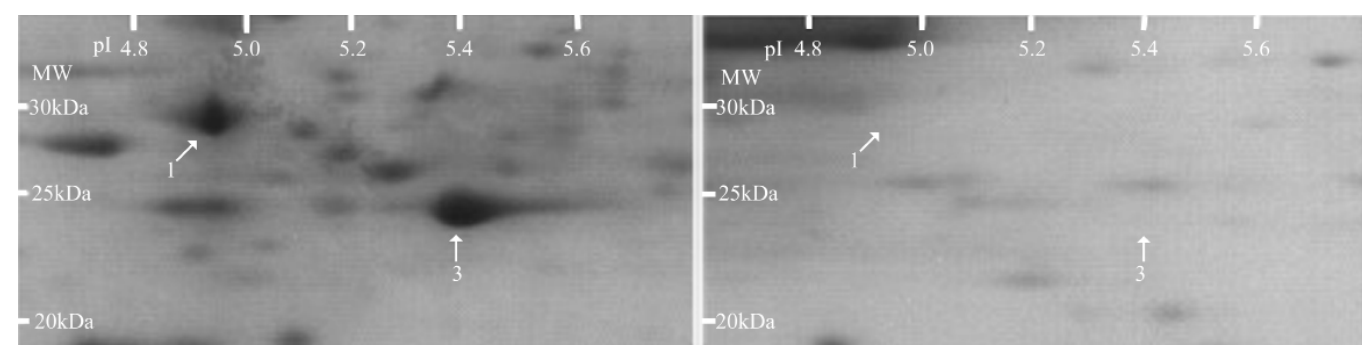

Figure 4. Two-dimensional electropherograms of wild type (left) and allC RNAi mutant (right). No1 and 3 represent two differential spots. The spots are identified by MALDI-TOF-MS/MS. The identities assigned are listed in Table 1. 

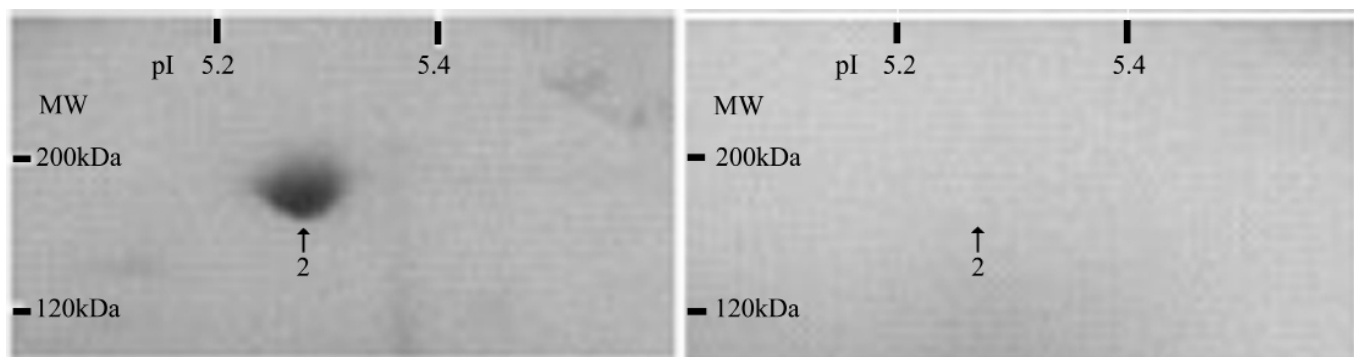

Figure 5. Two-dimensional electropherograms of wild type (left) and allC RNAi mutant (right). No. 2 represents one of differential spots. The spot is identified by MALDI-TOF-MS/MS. The identity assigned is listed in Table 1.

Table 1. Protein identifications for spots at position Nos. 1, 2 and 3 by MALDI-TOF-MS/MS.

\begin{tabular}{|c|c|c|c|c|c|}
\hline Spot No. & Protein identification & MW (Da) & pI & No. and sequence of peptide & Accession \\
\hline 1 & 14-3-3 protein & 28857 & 4.82 & $\begin{array}{l}3 \\
\text { K.DSTLIMQLLR.D/ } \\
\text { R.YLAEFATGNPR.K/ } \\
\text { K.AASDIAVTELPPTHPIR.L }\end{array}$ & gi|1197463 \\
\hline 2 & Myosin II heavy chain & 243872.7 & 5.47 & $\begin{array}{l}5 \\
\text { R.LVELELEDARR.N/ } \\
\text { K.SLKDTESNVLDLQR.Q/ } \\
\text { K.TQTEIGAAKLEDQIDELR.S// } \\
\text { K.LQGEYTELNEKFNSEVTAR.S/ } \\
\text { R.VAELEESLEDKSGTVNVEFIR.K }\end{array}$ & gi|167835 \\
\hline 3 & DdCAD-1 & 24139 & 5.4 & $\begin{array}{l}3 \\
\text { K.LTPPDSEIVSHLTVR.Q/ } \\
\text { K.NCTGESFEYNKGETVR.F/ } \\
\text { R.FNNGDKWNDKFMSCLVGSNVR.C }\end{array}$ & gi|1705539 \\
\hline
\end{tabular}

\section{DISCUSSION}

The downregulation of 14-3-3 protein expression could be one of the important factors contributing to the shortened cell cycle of allC RNAi mutants.

14-3-3 proteins were initially identified in 1967 as a family of acidic proteins in the mammalian brain (Moore and Perez, 1967). 14-3-3 proteins are a ubiquitous family of molecules that participate in protein kinase signaling pathways in all eukaryotic cells. The 14-3-3 proteins function as phosphoserine/phosphothreonine-binding modules and participate in phosphorylation-dependent protein-protein interactions that control progression through the cell cycle (Margolis et al., 2003), initiation and maintenance of DNA damage checkpoints (Stavridi et al., 2001; Yang et al., 2003), activation of MAP kinases (Light et al., 2002; Ory et al., 2003), prevention of apoptosis (Sunayama et al., 2005; Yoshida et al., 2005), and coordination of integrin signaling and cytoskeletal dynamics (Hashiguchi et al., 2000; Han et al., 2001).

The 14-3-3 family of highly conserved proteins consists of seven isotypes in human cells: $\beta, \gamma, \zeta, \sigma, \varepsilon, \eta$, and $\tau$ (Aitken, 2006), which are encoded by seven genes. In $D$. discoideum, these are only present in pairs: 14-3-3 (GI: 1197463) and type A von Willebrand factor domain-containing protein (GI: 66807689). 
The Cdc25 family of phosphatases comprises three isoforms: Cdc25A, B, and C. While $\mathrm{Cdc} 25 \mathrm{~A}$ is required for efficient S-phase entry, it also appears to play a role late in the cell cycle where increased expression can facilitate the transition between the G1/S and G2/M checkpoints (Blomberg and Hoffmann, 1999; Sexl et al., 1999; Molinari et al., 2000). The other two family members, Cdc25B and C, play important roles in governing entry into mitosis and the G2/M checkpoint (Millar et al., 1991). However, Cdc25B appears to play a more prominent role during the early portion of the $\mathrm{G} 2 / \mathrm{M}$ checkpoint, whereas $\mathrm{Cdc} 25 \mathrm{C}$ governs the later portions of the G2/M checkpoint (Donzelli and Draetta, 2003). All three of these isoforms have been shown to interact with the 14-3-3 protein, and these interactions play important roles in controlling cell cycle transitions (Peng et al., 1997; Forrest and Gabrielli, 2001; Chen et al. 2003).

The molecular "motor" that drives cells into mitosis is the cyclin $\mathrm{B} / \mathrm{Cdc} 2$ protein kinase. Throughout the cell cycle in animal cells, this kinase shuttles between the nucleus and cytoplasm, being primarily cytoplasmic, except during the $\mathrm{M}$ phase. In interphase cells, this kinase is maintained in an inactive state by phosphorylation on Thr-14 and Tyr-15 by the nuclear kinase Wee1 and the cytoplasmic kinase Myt1 (Lundgren et al., 1991; Parker et al., 1993; Liu et al., 1997). In addition, Cdc25C is phosphorylated on Ser-216 and is bound to 14-3-3 proteins at this time (Dalal et al., 1999), which appears to both inhibit the phosphatase activity and facilitate nuclear exclusion (Lopez-Girona et al., 1999; Graves et al., 2001). Entry into mitosis is accomplished by the release of Cdc25C from 14-3-3, and by dephosphorylation of the Ser-216 site by PP1 (Margolis et al., 2003). Intriguingly, mitotic entry is also accompanied by phosphorylation of Cdc25C on Ser-214 (Bulavin et al., 2003). The dual Ser-214 and Ser216 phosphorylated form of Cdc25C loses its ability to bind to 14-3-3, ensuring that once cells have entered mitosis, subsequent activation of checkpoint kinases cannot halt the process.

The downregulation of myosin II heavy chain expression could be one of the most important factors resulting in developmental interruption in allC RNAi mutants.

D. discoideum amoebae, which lack the myosin II heavy chain gene, are motile and aggregate to form rudimentary mounds, but do not undergo further morphological development (Manstein et al., 1989; Eliott et al., 1993). Myosin null cell aggregates fail to form tips (Eliott et al., 1993). In most wild-type strains, a tip forms after cells have collected into the mound, and acts as an organizing center that emits cAMP and directs further morphogenetic movements (Rubin and Robertson, 1975). Thus, tip formation is an essential part of D. discoideum development. It has been proposed that a subgroup of prestalk cells (pstA cells), initially distributed throughout the aggregate, sort out, migrating upwards to form a tip at the top of the mound (Williams et al., 1989; Esch and Firtel, 1991). The inability of myosin II null cells to form tips was also observed in synergy experiments, in which null cells stained with a fluorescent membrane dye were mixed with unstained wild-type cells. Null cells were absent from the extreme tips of mixed slugs and early culminates (Eliott et al., 1993). The abovementioned results suggest that the cells of $D$. discoideum amoebae, which lack myosin II, may have insufficient strength to generate sufficient force for the formation of tips.

In the present study, we observed an apparent difference between the actual value and theoretical value of the molecular weight of the myosin II heavy chain. These changes might be due to post-translational protein processing, such as proteolysis.

We believe that the downregulation of DdCAD-1 expression is not an important contributing factor for developmental interruption in allC RNAi mutants. The search for the origin of multicellularity usually begins with cell-cell adhesion molecules (CAMs) and substratum 
adhesion proteins (Bowers-Morrow et al., 2004; Harwood and Coates, 2004). Recent studies on CAMs have shown that they play very important roles in sensing environmental cues and in generating signals that regulate a diversity of cellular processes, including gene expression, cell proliferation, cell polarity, cell motility, and apoptosis (Siu et al., 2011). DdCAD-1 is one of the CAMs in D. discoideum. Although a lack of DdCAD-1 results in abnormal pattern formation in slugs and a reduction in spore yield, Dictyostelium cells are still able to complete development and form fruiting bodies (Wong et al., 2002).

\section{ACKNOWLEDGMENTS}

Research supported by the National Natural Science Foundation of China (\#30970316, \#30670226) and the Co-constructing Key Laboratory for Cell Differentiation Regulation by Henan and the Ministry of Science and Technology.

\section{REFERENCES}

Aitken A (2006). 14-3-3 proteins: a historic overview. Semin. Cancer Biol. 16: 162-172.

Blomberg I and Hoffmann I (1999). Ectopic expression of Cdc25A accelerates the G(1)/S transition and leads to premature activation of cyclin E- and cyclin A-dependent kinases. Mol. Cell Biol. 19: 6183-6194.

Bowers-Morrow VM, Ali SO and Williams KL (2004). Comparison of molecular mechanisms mediating cell contact phenomena in model developmental systems: an exploration of universality. Biol. Rev. Camb. Philos. Soc. 79: 611642.

Bulavin DV, Higashimoto Y, Demidenko ZN, Meek S, et al. (2003). Dual phosphorylation controls Cdc25 phosphatases and mitotic entry. Nat. Cell Biol. 5: 545-551.

Chen MS, Ryan CE and Piwnica-Worms H (2003). Chk1 kinase negatively regulates mitotic function of Cdc25A phosphatase through 14-3-3 binding. Mol. Cell Biol. 23: 7488-7497.

Dalal SN, Schweitzer CM, Gan J and DeCaprio JA (1999). Cytoplasmic localization of human cde25C during interphase requires an intact 14-3-3 binding site. Mol. Cell Biol. 19: 4465-4479.

Donzelli M and Draetta GF (2003). Regulating mammalian checkpoints through Cdc25 inactivation. EMBO Rep. 4: 671677.

Eliott S, Joss GH, Spudich A and Williams KL (1993). Patterns in Dictyostelium discoideum: the role of myosin II in the transition from the unicellular to the multicellular phase. J. Cell Sci. 104 (Pt 2): 457-466.

Esch RK and Firtel RA (1991). cAMP and cell sorting control the spatial expression of a developmentally essential celltype-specific ras gene in Dictyostelium. Genes Dev. 5: 9-21.

Forrest A and Gabrielli B (2001). Cdc25B activity is regulated by 14-3-3. Oncogene 20: 4393-4401.

Graves PR, Lovly CM, Uy GL and Piwnica-Worms H (2001). Localization of human Cdc25C is regulated both by nuclear export and 14-3-3 protein binding. Oncogene 20: 1839-1851.

Han DC, Rodriguez LG and Guan JL (2001). Identification of a novel interaction between integrin beta1 and 14-3-3beta. Oncogene 20: 346-357.

Harwood A and Coates JC (2004). A prehistory of cell adhesion. Curr. Opin. Cell Biol. 16: 470-476.

Hashiguchi M, Sobue K and Paudel HK (2000). 14-3-3zeta is an effector of tau protein phosphorylation. J. Biol. Chem. 275: 25247-25254.

Keilin J (1959). The biological significance of uric acid and guanine excretion. Biol. Rev. 34: $265-294$.

Light Y, Paterson H and Marais R (2002). 14-3-3 antagonizes Ras-mediated Raf-1 recruitment to the plasma membrane to maintain signaling fidelity. Mol. Cell Biol. 22: 4984-4996.

Liu F, Stanton JJ, Wu Z and Piwnica-Worms H (1997). The human Myt1 kinase preferentially phosphorylates Cdc2 on threonine 14 and localizes to the endoplasmic reticulum and Golgi complex. Mol. Cell Biol. 17: 571-583.

Loomis WF Jr. (1972). Role of the surface sheath in the control of morphogenesis in Dictyostelium discoideum. Nat. New Biol. 240: 6-9.

Lopez-Girona A, Furnari B, Mondesert O and Russell P (1999). Nuclear localization of Cdc25 is regulated by DNA damage and a 14-3-3 protein. Nature 397: 172-175.

Lundgren K, Walworth N, Booher R, Dembski M, et al. (1991). mik1 and wee1 cooperate in the inhibitory tyrosine 
phosphorylation of cdc2. Cell 64: 1111-1122.

Manstein DJ, Titus MA, De LA and Spudich JA (1989). Gene replacement in Dictyostelium: generation of myosin null mutants. EMBO J. 8: 923-932.

Margolis SS, Walsh S, Weiser DC, Yoshida M, et al. (2003). PP1 control of M phase entry exerted through 14-3-3-regulated Cdc25 dephosphorylation. EMBO J. 22: 5734-5745.

Millar JB, Blevitt J, Gerace L, Sadhu K, et al. (1991). p55CDC25 is a nuclear protein required for the initiation of mitosis in human cells. Proc. Natl. Acad. Sci. U. S. A. 88: 10500-10504.

Molinari M, Mercurio C, Dominguez J, Goubin F, et al. (2000). Human Cdc25 A inactivation in response to S phase inhibition and its role in preventing premature mitosis. EMBO Rep. 1: 71-79.

Moore BE and Perez VJ (1967). Specific Acidic Proteins of the Nervous System. In: Physiological and Biochemical Aspects of Nervous Integration (Carlson FD, ed.). Prentice-Hall, Inc., The Marine Biological Laboratory, Woods Hole, 343-359.

Ory S, Zhou M, Conrads TP, Veenstra TD, et al. (2003). Protein phosphatase 2A positively regulates Ras signaling by dephosphorylating KSR1 and Raf-1 on critical 14-3-3 binding sites. Curr. Biol. 13: 1356-1364.

Parent CA and Devreotes PN (1996). Molecular genetics of signal transduction in Dictyostelium. Annu. Rev. Biochem. 65: 411-440.

Parker LL, Walter SA, Young PG and Piwnica-Worms H (1993). Phosphorylation and inactivation of the mitotic inhibitor Wee1 by the nim 1/cdrl kinase. Nature 363: 736-738.

Peng CY, Graves PR, Thoma RS, Wu Z, et al. (1997). Mitotic and G2 checkpoint control: regulation of 14-3-3 protein binding by phosphorylation of Cdc25C on serine-216. Science 277: 1501-1505.

Rubin J and Robertson A (1975). The tip of the Dictyostelium discoideum pseudoplasmodium as an organizer. J. Embryol. Exp. Morphol. 33: 227-241.

Sexl V, Diehl JA, Sherr CJ, Ashmun R, et al. (1999). A rate limiting function of cdc25A for S phase entry inversely correlates with tyrosine dephosphorylation of Cdk2. Oncogene 18: 573-582.

Siu CH, Sriskanthadevan S, Wang J, Hou L, et al. (2011). Regulation of spatiotemporal expression of cell-cell adhesion molecules during development of Dictyostelium discoideum. Dev. Growth Differ. 53: 518-527.

Stavridi ES, Chehab NH, Malikzay A and Halazonetis TD (2001). Substitutions that compromise the ionizing radiationinduced association of $\mathrm{p} 53$ with 14-3-3 proteins also compromise the ability of p53 to induce cell cycle arrest. Cancer Res. 61: 7030-7033.

Sunayama J, Tsuruta F, Masuyama N and Gotoh Y (2005). JNK antagonizes Akt-mediated survival signals by phosphorylating 14-3-3. J. Cell Biol. 170: 295-304.

Sussman M (1987). Cultivation and synchronous morphogenesis of Dictyostelium under controlled experimental conditions. Methods Cell. Biol. 28: 9-29.

Urich K (1994). Comparative Animal Biochemistry. Springer-Verlag, Heidelberg.

Weijer CJ (2009). Collective cell migration in development. J. Cell Sci. 122: 3215-3223.

Williams JG, Duffy KT, Lane DP, McRobbie SJ, et al. (1989). Origins of the prestalk-prespore pattern in Dictyostelium development. Cell 59: 1157-1163.

Williams JG (2010). Dictyostelium finds new roles to model. Genetics 185: 717-726.

Wong E, Yang C, Wang J, Fuller D, et al. (2002). Disruption of the gene encoding the cell adhesion molecule DdCAD-1 leads to aberrant cell sorting and cell-type proportioning during Dictyostelium development. Development 129: 38393850 .

Xue DM and Hou LS (2012). Shortening of the cell cycle and developmental interruption in a Dictyostelium discoideum cell line due to RNAi-silenced expression of allantoicase. Genet. Mol. Res. 11: 1923-1933.

Yang HY, Wen YY, Chen CH, Lozano G, et al. (2003). 14-3-3 sigma positively regulates p53 and suppresses tumor growth. Mol. Cell Biol. 23: 7096-7107.

Yoshida K, Yamaguchi T, Natsume T, Kufe D, et al. (2005). JNK phosphorylation of 14-3-3 proteins regulates nuclear targeting of c-Abl in the apoptotic response to DNA damage. Nat. Cell Biol. 7: 278-285. 